\title{
Levantamentos ornitológicos no dossel da mata pluvial de terra firme
}

\author{
Richard O. Bierrergaard Jr. (')
}

\begin{abstract}
Resumo
De uma torre de $42 \mathrm{~m}$ de altura, observaram-se pássaros mal conhecidos, que vivem no dossel, e por cima dele, 131 espécies vistas ou ouvidas da torre, foram identificadas, sendo aqui incluida uma lista das mosmas. Uma delas, Haematoderis militaris, até então conhecida apenas no leste da Bacia Amazônica, foi registrada pela primeira vez, na Amazônia Central.
\end{abstract}

\section{INTRODUÇÃO}

A maneira de vida de muitas espécies que habitam o estrato supericr das matas pluviais é mal conhecida. As condições encontradas ofereceram uma rara oportunidade, para recotherem-se novas informações, sobre os pa. drões de atividade diária e anual, de muitas aves (mal conhecidas sob tais aspectos), e souro: a presença de espécies até agora conhecidas, só em outras regiões da Bacia Amazônica.

A região apresenta uma época seca (maio a novembro), cujo nível de precipitação é $732 \mathrm{~mm}$. A época chuvosa começa em dezembro e, geralmente, termina no início de maio. O nivel de precipitação nesta, é ao redor de $1369 \mathrm{~mm}$. A mata no local, tem cerca de $35 \mathrm{~m}$ de aitura, com algumas árvores emergentes, que chegam a 45 . Seus subestratos, são mais ou inenos abertos, caracteristicamente com muitas palmeiras acaules. Informaçōes minuciosas sobre os padrões climatológicos, solo, e composição da mata, encontram-se neste suplemento (Franken et al., 1982; Chauvel, 1982; Guillaument \& Kahn, 1982).

\section{MATERIAL E MÉtodos}

As observações foram feitas durante 21 dias do alto de uma torre, de $42 \mathrm{~m}$, situada na mata virgem, a uns $70 \mathrm{~km}$ ao norte de Manaus
(Bacia Modelo do INPA, Estrada ZF-2 Distrito Agropecuáric da SUFRAMA), com auxílio de binóculo $(10 \times 40)$ e de um telescópio de poder variável $(15-60 x)$ no período de julho de 79 à junho/ $/ 81$.

\section{RESULTADOS E COMENTÁRIOS}

Devido a fatores diversos, o pesquisador não pode fazer observações freqüentes como seria desejável. Embora a torre oferecesse uma oportunidace ótima de conhecerem-se as espécies do dcssel, houve a ciesvantagem do levartamento ser feito de um ponto fixo. Assim, levando-se em conta o fato da estrutura da mata, e da comunidade dos pássaros: serem. diferentes de um local para outro, a lista apresentada neste trabalho, não pode ter sentido quar.titativo. Várias aves, raramente vistas ou ouvidas da torre, são comuns a uns poucos quilômetros de distância. Também os pássaros dos subestratos, conhecidos apenas pela voz, têm cantos diferentes. Alguns são bem fortes e alcançam as copas. Outros, são como Snethlagea minor por exemplo, são muito co. muns nos subestratos, mas têm cantos tão fracos, que raramente aparecem na lista dos ouvidos da torre. Isto significa que o levanta mento da avifauna da região só pode ser feito combinando-se 'pesquisas de vários cantos, do chão ao dossel.

Análises quantitativas não foram feitas devido ao número variável de observadores que registraram as visitas dos pássaros, mas é bem claro que o nível de atividade destes, nas copas das árvores, ao redor da torre, é altamente variável. Houve um dia em que: 73 espéciess foram identificadas e vários outros em que apenas 250 foram.

Apesar desta variabilidade de um dia para outro, há um padrão geral de atividade diária.

(1) - Instituto Nacional de Pesquisas da Amazônia, Manaus; World Wildlife Fund - Washington, E.U.A. 
Representantes de algumas espécies, começam a cantar a partir das 5:30 h, e muitas outras juntam-se a eles entre $6: 00$ e 7:00 h. (o sol nasce entre 5:45 e 6:00 h. ciurante 0 ano). Entre 6:00 e 7:00 h. começam a voar os Psittaciformes (papagaios, araras, etc). Das 7:00 às 9:00 h. há menos aves cantando, mas muitas voando, e andando pelas copas. As andorinhas (famílias Hirundinidae e Apodidae) aparecem a partir das $7: 30 \mathrm{~h}$. Das $8: 30 \mathrm{~h}$. em diante os os gaviões e urubus têm condições de voar muito alto no ar quente, e aparecem acima da mata. Daí em diante, reina o silêncio, com os papagaios alimentando-se ou andando em busca de árvores com frutos.

De vez em quando, aparecem bandos mistos incluindo espécies insetivoras ae várias famílias (Galbulidae, Tyrannidae, Vireonidae. Picidae, Formicariidae, Dendrocolaptidae, Sylvidae), ou frugívoras e nectarívoras (Thraupidae). Havendo uma árvore com flores ou fru. tas comestíveis, a atividade pode ser contínue, com diversas espécies chegando e desaparecendo rapidamente.

Encontra-se a seguir, uma lista preliminar das espécies vistas da torre, com anotações correspondentes a cada uma. Várias somente andam nos estratos inferiores, mas foram reconhecidas pelos cantos ou vistas quando o observador subiá à torre. A taxonomia segue De Schauense \& Phelps (1978); os nomes vul. gares, Manual de anilhamento de aves (1981), ou são os usados pelos mateiros da região.

\section{TINAMIDAE}

Crypturellus variegatus - Chororão/Nambú Re lógio. Comum, no chão, pela voz.

\section{CATHARTIDAE}

Sarcoramphus papa - Urubu-rei. Uma voz só. Cathartes melambrotus - Urubu-de cabeçaamarela. Incomum.

\section{ACCIPITRIDAE}

Elanoides forficatus - Gavião-tesoura. Comum. Harpagus bidentatus - Incomum.

Accipiter poliogaster - Tauató-pintado. Uma vez só.

Buteo platypterus - Uma vez só, 3 adultos e 1 jovem (novembro).

Migrante da América do Norte.
Leucopternis albicollis - O gavião mais comum em cima dessa mata.

Buteogallus urubitinga - Gavião-preto. In comum.

Morphnus guianensis - Uiraçu-falso. 1 jovem só (setembro).

Um ninho com dois ovos foi descoberto em abril de 1980 a uns $4 C \mathrm{Km}$ para o nordeste (Bierrergaard, s.d.) em prep.).

Harpia harpyja - Gavião real. 1 joven (julho) e 1 adulto.

\section{FALCONIDAE}

Micrastur gilvicollis - Gavião-caburé. Subestratos. Voz.

M. semitorquatus - Tem-tem. Subestratos Voz (segundo $\mathrm{H}$. Sick).

Daptrius americanus - Cancão. Comum. Anda em grupos sociais de 3 até 10 indivíduos. Bem barulhentos.

Falco rufigularis - Coleirinha. Uma vez só.

\section{CRACIDAE}

Crax alector - Mutum-do-»orte. Uma vez só. Visto em baixo.

\section{PHASIANIDAE}

Odontophorus gujanensis - Uru. No chão. Voz.

\section{COLUMBIDAE}

Columba subvinacea - Comum.

C. plumbea - Pomba-amargosa. Comum.

Leptotila verreauxi - Juriti-pupu. Uma vez só. Voz (segundo J. Fitzpatrick).

\section{PSITTACIDAE}

Ara ararauna - Arara-Canindé. Incomum.

A. macao - Arara-Piranga. Interessante que nunca foi visto da torre mas a poucos $\mathrm{kms}$ da torre pela ZF-2 é mais ou menos comum.

A. chloroptera - Arara-vermelha. Comum.

Forpus cf. sclateri - Tuim. Uma vez só.

Brotogeris chrysopterus - Periquito. Bem cri mum. Anda em bandos de 5 até 20, às vezes voando alto.

Touit purpurata - Incomum. Difícil ver como voa muito rapidamente pelas copas em duplas ou bandos até 6 .

Pionopsitta caica - Comum. Voa muito perto das copas em grupos muito pequenos.

Pionus menstruus - Maitaca-de-cabeça-azul. Muito comum. Voa até $50 \mathrm{~m}$ em cima das copas, às vezes em bandos de até 25 .

P. fuscus - Maitaca-Bronzeada. Muito comum. Como P. menstruus, voa alto, também em bandos grandes. 
Amazonas autumnalis diadema - Papagaio-diadema. Segundo Forshaw (1973) só existe entre os rios Solimões e Negro, mas visto por Willis (1977) na Reserva Ducke e é um dos papagaios mais comuns na Bacia Modelo. Voa em bandos pequenos.

A. farínosa - Comum. Comportamento como A. autumnalis

Deroptyus accipitrinus - Anacá. Comum. Anda em bandos até 6 indivíduos perto das copas das árvores.

\section{CUCULIDAE}

Piaya melanogaster - Chincoã-de-bico-vermetho. Incomum. Anda por dentro das copas e cipós densos.

\section{APODIDAE}

Chaetura spinicauda - Muito comum. Voando em cima da mata buscando insetos voadores.

Reinarda squamata - Andorinha-da-palmeira. Uma vez só.

\section{TROCHILIDAE}

Campylopterus largipennis - Uma vez só.

Florisuga mellivora - A Beija-flor mais comum no dossel dessa mata.

Anthracothorax nigricollis - Beija-flor-de-vestepreta. Uma vez só tirando insetos de uma teia de aranha.

Heliothrix aurita - Beija-flor-verde-e-branco. Uma vez só.

(Várias outras espécies foram vistas mas não idencificadas].

\section{IROGONIDAE}

Trogon melanurus - Surucuá-de-cauda-escura. Esta especie tanto quanto as outras na família são comuns mas aparecem raramente no dossel da mata.

T. viridis - Surucuá-violeta-grande

T. collaris - Voz (segundo J. Fitzpatrick)

T. violaceus - Surucuá-violeta-pequeno

\section{MOMOTIDAE}

Momotus momota - Juruva. Comum nos subestratos. Voz só.

\section{GALBULIDAE}

Galbula albirostris - Ariramba-da-mata. Comum em baixo.

G. dea - Bico-de-agulha. Muito comum. Geralmente pousada num galho esperando insetos voadores. Quando aparece um bando misto na área, junta-se ao mesmo.

\section{BUCCONIDAE}

Notharctus macrorhychus - Capitão-da-mata. Raramente faltam alguns indivíduos desta espécie pousados perto da torre, buscando insetos andando pelas folluas das copas das árvores.

\section{CAPTITONIDAE}

Capito niger - Pica-pau. Incomum.

\section{RAMPHASTIDAE}

Pteroglossus viridis - Araçari-de-barriga-amarela. Uma vez só.

Selinedera culik - Incomum.

Ramphastos vitellinus - Tucano-de-bico-preto. Muito comum. Houve poucos dias quando este pássaro não estava cantando ou voando ao redor da torre.

R. tucanos - Tucano-de-peito-branco. Até mais comum que $\mathbf{R}$. vitellinus. Muitas vezes cantando junto com $\mathbf{R}$. vitellinus.

\section{PICIDAE}

Piculus flavigula - Geralmente anda com bandos mistos nos subestratos, mas aparece, de vez em quando, nas copas.

P. chrysochlorus - uma vez só.

Celeus grammicus - uma vez só.

C. undatus - incomum .

C. torquatus - Comum. Voz (segundo J. Fitzpatrick).

Campephilus rubricollis - Comum. De manhã cedo fica num galho morto e bate o bico duas vezes rapidamente. Este sinal alcança longe.

\section{DENDROCOLAPTIDAE}

Deconychura longicauda - Uma vez só, em baixo.

Sittasomus griseicapillus - Arapaçu-verde. Incomum.

Nasica longirostris -- Arapaçu. Uma vez só, em baixo.

Hylextetastes perroti - Pica-pau-vermelho. Incomum nos subestratos.

Dendrocolaptes picumnus - Uma vez só, se guindo formigas de correição no chão.

\section{FORMICARIIDAE}

Thamnomanes caesius - Comum em baixo, em bandos mistos.

Myrmotherula brachyura - Incomum, mas sempre nas copas.

Herpsilochmus stícturus - Como M. brachyura.

Terenura spodioptila - Incomum, geralmente nas copas. 
Cercromacra cinarescens - Incomum. Voz (segundo F. Novaes). Muito difícil ver, andáa nas copas e cipós.

Hypocnemis cantator - Voz só. Muito comum no chão nas quedas de árvores.

Percnostola rufifrons - Voz. Comum no chão.

Pithys albifrons - Uma vez só, seguindo formigas de correição.

Gymnopithys rufigula - Com Pithys albifrons são uns dos pássaros mais abundantes no chão da mata desta região (Bierrergaard, em prep. B).

Formicarius analis - No chão. Voz.

Hylopezus macularia - No chão. Voz.

\section{COTINGIDAE}

Cotinga cayana - Anambé-azul. Incomum.

C. cotinga - Anambé-roxo. Uma vez só. Xipholena punicea - Babaçú. Muito comum

Lipaugus vociferans - Cricrió/Seringueiro. Anda nos subestratos. Muito comum. Por causa da voz alta é, sem dúvida, o pássaro mais conspícuo nas matas da região.

Pachyramphus marginatus - Uma vez só.

P. surinamus - Uma vez só (segundo J. Fitzpatrick). Segundo De Schauensee (1970) só conhecido no Leste do Brasil ao Norte do Rio Amazonas.

Tityra cayana - Araponguinha. Uma vez só.

Perissocephala tricolor - Urutaui. Incomum. Voz.

Haematoderis militaris - Anambé-vermelho. Há poucos individuos, mas sempre se encontram ao redor da torre. A primeira vez que foi visto na região foi no dia 27 de julho de 1979 (segundo T. Lovejoy, D. Oren, D. Moskowitz e J. Zickefoose). Antigamente só conhecido no Leste da Bacia Amazônica (De Schauensee, 1970).

\section{PIPRIDAE}

Pipra pìpra - Pipira-de-cabeça-branca. Comum em baixo, visto só uma vez buscando frutas nas copas perto da torre.

Tyranneutes virescens - Uma vez só.

Piprites chloris - Uma vez só.

Schiffornis turdinus - Comum nos subestratos. Voz.

\section{TYRANNIDAE}

Sirystes sibilator - Suiriri-assobiador. Uma vez só.

Muscivora tyrannus - Tesourinha. Incomum. Setembro e julho. Migrantes?

Conopias parvas - Comum. Muitas vezes com bandos mistos de pássaros insetívoros. Anda de copa em copa, geralmente pousando nos galhos mais altos.

Myiodonastes maculatus - Uma vez só.
Rhytipterna simplex - Voz. Anda nos subestratos.

Tolmomyias assimilis - Incomum.

T. poliocephalus - Incomum.

Snethlagea minor - Voz. Anda nos estratos inferiores.

Capsiempis flaveola - Marianinha-amarela. Uma vez só (segundo J. Fitzpatrick) ali. mentando filhotes em janeiro.

Myiopagis gaimardii - Incomum.

M. caniceps - Gurarcava-cinzenta. Uma ve? só. (segundo J. Fitzpatrick)

Phyllomyais griseiceps - Uma vez só (segundo Fitzpatrick).

Tyranniscus gracilipes - Incomum.

Ornithion inerme - Incomum.

HIRUNDINIDAE

Progne sp. - Andorinha. Uma vez só

\section{IROGLODYTIDAE}

Microcerculus bambla - Incomum. Anda no chão. Voz.

Cyphorhinus arada - Uirapuru. Como $\mathbf{M}$ bambla.

\section{TURDIDAE}

Turdus albicollis - Sabiá-coleira. Comum no chão. Voz.

\section{SYLVIIDAE}

Polioptila plumbea - Incomum. Anda pelos galhos interiores das copas com bandos mistos de pássaros insetivoros.

\section{VIREONIDAE}

Smaragdolanius leucotís - Incomum. Anda com bandos mistos de pássaros insetívoros.

Hylophilus ochraceiceps - Mais comum em bandos mistos nos subestratos, mas aparece nas copas.

H. thoracicus - Uma vez só (segundo Fitzpatrick).

\section{ICTERIDAE}

Psarocolius viridis - Japo/Japu-verde. Comum. Icterus chrysocephalus - Rouxinol-do-rio-negro. Incomum.

\section{PARULIDAE}

Dendroica striata - Uma vez só. Janeiro. Migrante da América do Norte. Também visto por Willis (1977) na Reserva Ducke.

\section{THRAUPIDAE}

Cyanerpes nitidus - A espécie mais rara deste gênero. Como as outras anda em bandos pequenos, buscando frutas pequenas e flores. 
C. cyaneus - A espécie mais comum do gênero.

C. cearuleus - Tem-tem-do-sspirito-santo. Incomum.

Chlorophanes spiza - Sai-tucano. Comum.

Dacnis cayana - Sai-azul. Muito comum.

D. lineata - As vezes se encontra numa árvo:e florescente junto com todas as outras espécies desta família, em cima na lista. Incomum.

Tangara velia - Saíra-diamante. Incomum.

T. chilensis - Sete-cores. Muito comum. Geralmente anda em bandos pequenos de uma espécie apenas, mas, às vezes com outras espécies deste gênero. Numa árvore com frutas pequenas ou em cipó de Ficus $s p$. Encontra-se alimentando-se com muitas outras espécies.

T. punctata - Negaça. Como T. chilensis, mas menos comum.

Euphonia minuta - Uma vez só.

E. cayennensis - Uma vez só.

Thraupis episcopus - Sanhaçu-azul. Um pássaro mais comum na capoeira e nas áreas abertas. Visto da torre duas vezes só.

T. palmarum - Sanhaçu-de-coqueiro. Também de capoeira. Espaços abertos, etc. Uma vez só.

Tachyphonus surinamus - Pipira. Duas vezes só. Mais comum nos subestratos, andando em bandos pequenos desta espécie só.

T. cristatus - Tiê-galo. Mais comum nas copas das árvores, às yezes em bandos mistos.

T phoenicius - Uma vez só.

Hemithraupis flavicollis - Incomum. Anda em bandos mistos.

Lamprospiza melanoleucus - Incomum. Anda em bandos pequenos de uma espécie só.

\section{FRINGILLIDAE}

Caryothraustes canadensis - Furriel. Comum Sempre anda em bandos de 4 até 10 indivíduos de uma espécie só.

Cyanocompsa cyanoides - Azulão. Incomum Voz. Anda no chão.

\section{Agradecimentos}

O apoio para este trabalho veio do Instituto Nacional de Pesquisas da Amazônia e World Wildlife Fund-U.S., O Programa "Man and the Bicsphere" providenciado pela agência para Desenvolvimento Internacional dos E.U.A. e O.U.S. National Park Service pelo "Cooperative Agreement CX-0001-09-0041". Este trabalho é $o n^{0} 7$ na série do Projeto Tamanho
Mínimo Crítico de Ecossistemas (Minimum Critical Size of Ecosystems) do World Wildlife Fund-U.S./ NSF e INPA/CNPq.

\section{SUMMARY}

Observations were made of birds in and above the canopy from a $42 \mathrm{~m}$ tower which offers a rare oportunity to study these poorly known canopy species. A brief description of the pattern of daily activity and an anotated list of the 131 species seen or heard from the tower are presented. The presence of Haematederis militaris represents a significant range extension from the eastern Amazonian basin.

\section{REFERENCIAS BIBLIOGRAFICAS}

BIERREGAARD, R.O. Jr.

s.d. - Nesting behaviour of the Guiana Crested Eagle (Morphnus guianensis). Em preparação (A).

- Sample heterogeneity and preliminary effects of isolation on understory tropical forest birds. Em preparação (B).

CHAUVEL, A.

1982 - Os latossolos amarelos, álicos, argilosos dentro dos ecossistemas das bacias experimentais do INPA e da Região vizinha. Acta Amazonica, 12 (3): Suplemento, p.

DE SCHAUENSEE, R.M.

1970 - A guide to the birds of South America. Livingston Publishing. Wynnewood, PA. 470p.

DE SChAuENSEE, R.M. \& E.W.H. PHELPS, Jr.

1978 - A guide to the birds of Venezuela. Princeton Univ. Press. Princeton, N.J. 424p.

FORSHAW, J.M.

1973 - Parrots of the world Landsdowne Press. Melbourne, Australia, 584p.

FRANKEN, W.; LEOPOLDO, P.R.; MATSUI, E.;

RIBEIRO, M.N.G.

1982 - Interceptação das precipitações em floresta Amazônica de Terra Fisme. Acta Amazonica, 12 (4): Suplemento,

GUILLAUMET, J. \& KAHN, F.

1982 - Estrutura e dinamismo da floresta. Acta Amazonica, 12 (3): Suplemento, p.

1981 - Manual de Anilhamento. Aves. Brasilia, CEMAVE, 105p.

WILI.IS, E.O.

1977 - Lista preliminar das aves da parte Noroeste e áreas vizinhas da Reserva Ducke, Amazonas, Brasil. Rev. Brasil. Biol., 37 (3): 585601.

(Aceito para publicação em 08/03/82) 